\title{
Efektivitas Pesan Teks dengan Cipher Substitusi, Vigenere Cipher, dan Cipher Transposisi
}

\author{
M. Azman Maricar ${ }^{1}$, Nyoman Putra Sastra ${ }^{2}$
}

\begin{abstract}
This research aims to determine how effective a text-based message security with classical cryptography methods such as Substitution, Vigenere, and Transposition. With implementation of crypthography method is expected to be able to minimize the tapping against the text message. These three methods, each will be in combine and compared the effectiveness based on the file size and time process. There are seven combinations of the three methods. The results of effectiveness testing showed that, the largest file size is a combination of Substitution, Vigenere, and Transposition of namely $11 \mathrm{~Kb}$, while the smallest is the Substitution and also Vigenere namely 5 $\mathrm{KB}$. Based on the longest process is the Substitution, Vigenere, and Transposition of namely 1.54 seconds, while the fastest is the Substitution namely 0.37 seconds. From the entire combination, entirely successfully to the process of encryption and decryption in order to restore the cipher text into original plain text.
\end{abstract}

Intisari- Penelitian ini bertujuan untuk mengetahui efektivitas suatu keamanan pesan berbasis teks dengan metode kriptografi klasik seperti Substitusi, Vigenere, dan Transposisi. Dengan penerapan metode kriptografi, diharapkan mampu untuk meminimalisasi terjadinya penyadapan terhadap pesan teks. Ketiga metode tersebut, masing-masing akan di kombinasikan dan dibandingkan efektivitasnya berdasarkan ukuran file dan waktu proses. Terdapat tujuh kombinasi dari ketiga metode tersebut. Hasil pengujian efektivitas didapatkan hasil bahwa, ukuran file terbesar adalah kombinasi Substitusi, Vigenere, dan Transposisi yaitu $11 \mathrm{~Kb}$, sedangkan yang terkecil adalah Substitusi dan juga Vigenere yaitu $5 \mathrm{~Kb}$. Berdasarkan waktu proses terlama adalah Substitusi, Vigenere, dan Transposisi yaitu 1.54 detik, sedangkan yang tercepat adalah Substitusi yaitu 0.37 detik. Dari seluruh kombinasi yang ada, seluruhnya berhasil untuk proses enkripsi dan dekripsi guna mengembalikan cipher text menjadi plain text yang asli.

Kata Kunci- Efektivitas, Kriptografi Klasik, Komunikasi, Pesan Teks, Substitusi, Transposisi, Vigenere.

\section{PENDAHULUAN}

Perkembangan teknologi yang semakin maju, menyebabkan proses komunikasi antar manusia maupun kelompok tidak harus dilakukan secara tatap muka atau bertemu secara langsung [1]. Hal tersebut digantikan dengan peran teknologi yang menyediakan fasilitas untuk berkomunikasi dengan basis teks. E-Mail, Short Message Service (SMS), WhatsApp, LINE, BlackBerry Messenger (BBM), We Chat, fitur-fitur Chatting pada media sosial, dan berbagai aplikasi lainnya merupakan aplikasi atau fasilitas untuk menunjang komunikasi berbasis teks.

\footnotetext{
${ }^{1}$ Magister Teknik Elektro, Universitas Udayana Kampus Sudirman, Denpasar-Bali (tlp: 0361-239559; fax: 0361-239599; e-mail:m.azman.maricar@gmail.com)

${ }^{2}$ Magister Teknik Elektro, Universitas Udayana Kampus Sudirman, Denpasar-Bali (tlp: 0361-239559; fax: 0361-239599; e-mail: putra.sastra@unud..ac.id)
}

M. Azman Maricar: Keamanan Pesan Teks Dengan ...
Perkembangan teknologi yang semakin maju tersebut, tentunya memiliki celah bagi seseorang untuk melakukan suatu penyadapan terhadap hal-hal tertentu yang berkaitan dengan teknologi, karena sampai saat ini belum ada teknologi yang benar-benar sempurna. Hal-hal tesebutlah yang menyebabkan diperlukannya suatu metode keamanan. Cipher Substitusi, Vigenere Cipher, dan Cipher Transposisi merupakan beberapa metode keamanan yang termasuk kedalam kategori kriptografi tradisional. Metode-metode tersebut mampu diterapkan untuk keamanan pesan berbasis teks.

Penerapan ketiga metode tersebut, dianggap mampu menjadi solusi untuk meningkatkan keamanan setiap pesan teks yang digunakan setiap orang untuk berkomunikasi. Alasannya, penyadapan yang terjadi terhadap komunikasi melalui pesan teks, yang mengakibatkan privasi seseorang dapat diketahui secara bebas oleh orang lain. Selain melakukan kombinasi terhadap ketiga metode tersebut, akan dilakukan juga kombinasi dua metode (Cipher Substitusi dan Vigenere Cipher, Cipher Substitusi dan Cipher Transposisi, serta Vigenere Cipher dan Cipher Transposisi), dan menerapkan masing-masing metode secara terpisah, guna melakukan perbandingan mengenai efektivitas kombinasikombinasi yang ada.

\section{STUDI LITERATUR}

Penelitian [1] merupakan penelitian yang dilatarbelakangi oleh adanya ancaman terhadap aspek keamanan data maupun informasi dari kemajuan teknologi pada bidang komunikasi. Solusi yang ditawarkan pada penelitian ini adalah implementasi kriptografi klasik yaitu, Algoritma Caesar Cipher pada teks yang dikirimkan melalui aplikasi chat. Hasil yang didapatkan dari proses pengujian adalah proses enkripsi dan dekripsi dengan Algoritma Caesar Cipher dapat menjaga kerahasiaan data.

Penelitian [2] memiliki tujuan untuk mengamankan transfer data saat proses backup data dari server utama menuju ke server backup melalui jaringan LAN dengan menggunakan algoritma DES dan AES. Kedua metode tersebut dibandingkan dari segi performa untuk mendapatkan metode yang lebih baik, sehingga pada saat komputasi tidak membebani server.

Perbandingan metode Vigenere dan Affine untuk pesan rahasia, dilakukan oleh [3]. Penelitian ini bertujuan untuk mendapatkan perbedaan tingkat keamanan dan mencari metode yang tepat serta lebih baik dari dua metode yaitu Vigenere dan Affine. Berdasarkan pengujian kedua metode menghasilkan output data yang tersamarkan melalui proses enkripsi. Perbedaan berdasarkan kunci yang digunakan, Vigenere menggunakan kunci berupa huruf, sedangkan Affine berupa angka bilangan prima dan memiliki dua input-an kunci. Dilihat dari sisi keamanan, kedua metode memiliki keamanan 
yang baik. Untuk Affine, memiliki kelebihan dua input-an kunci, hanya saja untuk kunci yang berupa bilangan prima, masih mudah ditebak karena jumlahnya yang terbatas. Sedangkan pada Vigenere hanya dengan satu kunci tetapi memiliki kebebasan untuk mengisi kunci tanpa dibatasi oleh panjang kunci dan jenis karakternya, baik itu berupa huruf maupun berupa angka.

Penelitian [4] ini membuat suatu sistem yang dapat mengamankan data dengan mengimplementasikan ilmu kriptografi untuk pesan teks, isi file dokumen, dan file dokumen dengan menggunakan Algoritma Advanced Encryption Standard. Hasil dari penelitian ini adalah pengguna dapat mengenkripsi suatu pesan teks, disimpan menjadi sebuah file dokumen, dan isinya di enkripsi lagi. Hasil dari proses enkripsi terhadap isi file dokumen tersebut, di enkripsi kembali, di kompresi, disembunyikan pada sebuah file citra, agar keamanan data dan informasi dapat terjaga karena sudah dilengkapi dengan sandi yang berlapis.

Penelitian [5] memiliki tujuan untuk memungkinkan pengguna untuk melakukan proses enkripsi dan menghasilkan output yang lebih kompleks, sehingga lebih sulit dipecahkan. Hasil dari penelitian ini adalah menghasilkan prototype aplikasi yang telah menerapkan Algoritma Kriptografi Kunci Simetris yang sudah dimodifikasi dengan Vigenere Cipher, dimana aplikasi ini menghasilkan cipher text yang sulit untuk di dekripsikan.

Penelitian [6], [7], dan [8], merupakan penelitian-penelitian yang bertujuan membuat aplikasi yang mengimplementasikan kriptografi. Aplikasi yang dibuat pada penelitian [6] menggunakan VB.Net 2008 dengan metode kriptografi klasik substitusi. Penelitian [7] menggunakan platform mobile dengan algoritma enkripsi berlapis, yaitu Caesar, Transposisi, Vigenere, dan Blok Cipher dengan tujuan agar lebih sulit dipecahkan. Sedangkan penelitian [8] dikembangkan dengan Microsoft Visual Basic 6.0, dan metode yang digunakan adalah Algoritma Transposisi Kolom. Tujuan dari penelitian ini adalah merancang dan mengetahui proses enkripsi dan dekripsi file. Transposisi kolom memiliki kelemahan pada penentuan kata sandi dan membutuhkan waktu yang cukup lama dalam proses enkripsi, jika panjang plain text memiliki panjang lebih dari 100 karakter.

Penelitian [9] menggunakan Enkripsi Vigenere Cipher dan Transposisi Pada Aplikasi Client Server Chatting. Tujuan dari penelitian ini adalah melakukan pengamanan data yang dikirimkan melalui jaringan ke server yang rentan dan cenderung diserang oleh hacker. Hasil yang didapatkan adalah meningkatnya keamanan pengiriman pesan dengan menggabungkan vigenere dan transposisi.

Penelitian [1-9] mengimplementasikan berbagai algoritma enkripsi dengan bermacam tujuan, tetapi tidak satupun dari penelitian tersebut membahas tentang efektivitas penggunaan enkripsi dengan tujuan untuk mendapatkan kombinasi metode yang memiliki kompleksitas algoritma. Penelitian ini disamping mengkombinasikan tiga metode (Substitusi, Vigenere, dan Transposisi), juga mengkombinasikan metode satu dengan metode lainnya, guna mendapatkan perbandingan efektivitas dari masing-masing kombinasi yang diukur dengan ukuran file dan waktu pemprosesan yang diperlukan. Agar lebih terstruktur, pada bagian selanjutnya akan dibahas (3) desain penelitian, (4) hasil dan analisa, dan terakhir (5) kesimpulan.

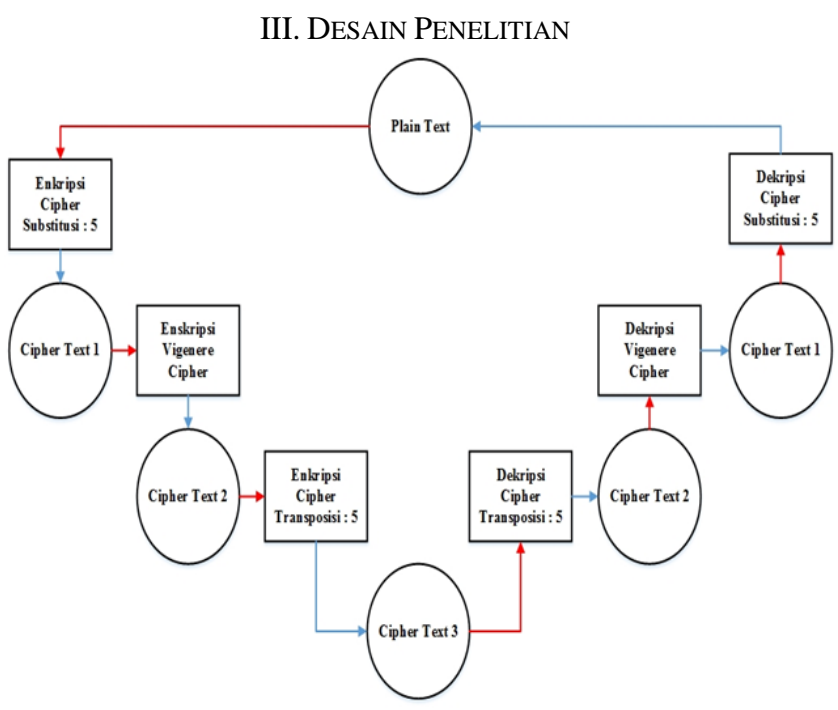

Gambar 1 : Desain Penelitian

Gambar 1 merupakan desain penelitian yang dilakukan. Plain text akan di enkripsi dengan teknik substitusi untuk menghasilkan cipher text 1 . Cipher text 1 tersebut selanjutnya di enkripsi lagi dengan vigenere cipher untuk mendapatkan cipher text 2. Cipher text 2 tersebut akan di enkripsi untuk terakhir kalinya dengan transposisi untuk mendapatkan cipher text 3. Cipher text yang sudah didapatkan tersebut akan di proses dekripsi untuk mendapatkan plain text seperti semula. Selain kombinasi ketiga metode tersebut, akan dikombinasikan metode satu dengan yang lainnya. Selanjutnya, istilah-istilah dan algoritma kriptografi yang digunakan pada penelitian ini akan dibahas.

\section{A. Kriptografi}

Secara umum, kriptograi dapat diartikan sebagai suatu bidang ilmu yang memiliki kesenian dalam menjaga kerahasiaan dari suatu data atau informasi dengan cara mengubahnya kedalam sesuatu yang tidak memiliki makna, sehingga tidak dapat dimengerti oleh seseorang yang tidak memiliki hak atas data atau inormasi tersebut [2]. Kriptografi sangat erat kaitannya dengan keamanan, dimana salah satu solusi yang menunjang keamanan adalah kata kunci, yang dalam beberapa kasus dibuat dengan sangat mudah agar mudah mengingat, namun mengakibatkan tingkat keamanan yang cenderung lemah [10].

\section{B. Enkripsi, Dekripsi, dan Cipher}

Enkripsi, dekripsi, dan cipher merupakan beberapa istilah penting dalam kriptografi, yang pengertian masing-masingnya sebagai berikut :

1) Enkripsi: proses atau mekanisme untuk mengubah sebuah pesan dari yang dapat dimengerti menjadi pesan yang tidak 
Majalah Ilmiah Teknologi Elektro, Vol. 17, No. 1,Januari -April 2018

DOI: https://doi.org/10.24843/MITE.2018.v17i01.P08

dapat dimengerti dengan sebuah kode/metode tertentu [1,3,4].

Dengan adanya enkripsi suatu data akan diacak dengan sebuah kunci enkripsi untuk menjadi susunan karakter yang tidak bermakna bagi seseorang yang tidak memiliki kunci untuk proses dekripsinya [1].

2) Dekripsi: lawan dari enkripsi, yaitu proses atau mekanisme untuk mengubah pesan yang awalnya tidak dapat dimengerti menjadi pesan yang dapat dimengerti, dengan menggunakan kode/metode tertentu [1,3,4]. Dengan menggunakan kunci dekripsi, seseorang akan dapat mengembalikan pesan yang asli [1].

3) Cipher: kunci yang digunakan sebagai aturan atau fungsi matematika yang digunakan pada proses enkripsi dan dekripsi $[3,4]$.

\section{Substitusi Cipher}

Proses keamanan dengan melakukan pergantian karakter yang terdapat pada sebuah teks menjadi karakter yang lain. Karakter yang diganti dapat berupa angka maupun huruf juga [1]. Konsep kerja dari substitusi cipher ditunjukan pada Gambar 2 sebagai contoh kerja substitusi cipher dengan pergeseran 3 .

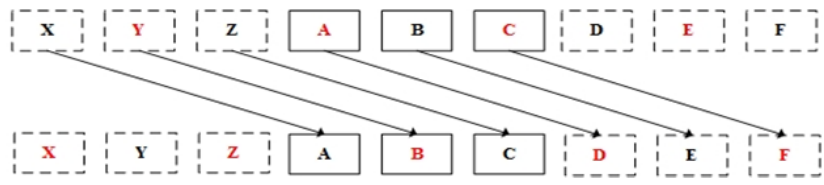

Gambar 2 : Konsep Kerja Substitusi Cipher

\section{Vigenere Cipher}

Vigenere Cipher merupakan metode untuk proses membuat kata sandi dari sebuah teks berdasarkan huruf-huruf pada kata kunci deretan sandi Caesar. Metode ini pertama kali dikemukakan oleh Blaise de Vigenere yang merupakan seorang diplomat sekaligus kriptologis asal Perancis pada tahun 1586 [5]. Bujur sangkar Vigenere ditunjukkan pada Gambar 3 [6].

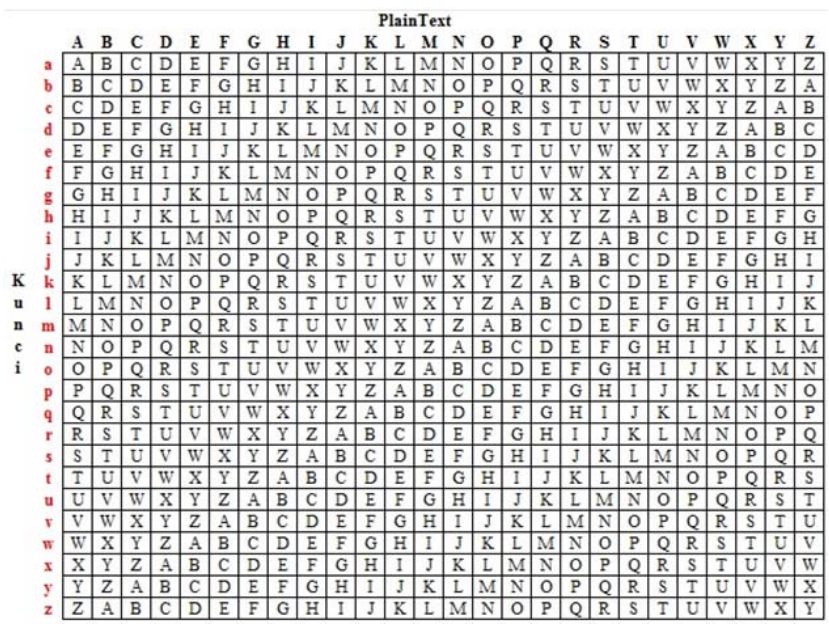

M. Azman Maricar: Keamanan Pesan Teks Dengan ...

Gambar 3 : Bujur Sangkar Vigenere

\section{E. Transposisi Cipher}

Proses keamanan dengan melakukan pengubahan posisi atau letak karakter dan untuk mengembalikan suatu pesan, data atau informasi dalam bentuk aslinya, cukup dengan mengembalikan posisi karakter seperti awal sebelum dilakukan transposisi [7,9].

Pengertian lain dari tranposisi cipher adalah teknik untuk memindahkan ataupun merotasi setiap karakter dalam teks dengan model-model tertentu. Prinsip pada transposisi berlawanan dengan substitusi yang posisi karakternya tetap hanya diganti oleh karakter lainnya, sedangkan transposisi sendiri karakter tidak diganti namun diubah posisinya [8].

Konsep kerja dari transposisi cipher ditunjukan pada Gambar 4 sebagai contoh plain text yang ada dituliskan secara horisontal dengan panjang karakter 3 dan untuk mendapatkan ciphertext dengan membaca secara vertikal.

Plain Text : AKU DAN KAU

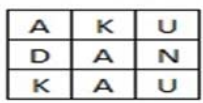

Cipher Text

ADKKAAUNU

Gambar 4 : Konsep Kerja Transposisi Cipher Horinsontal

\section{HASIL DAN ANALISIS}

Sumber data dalam penelitian ini didapatkan dari chat WhatsApp, ditunjukkan pada Gambar 5.

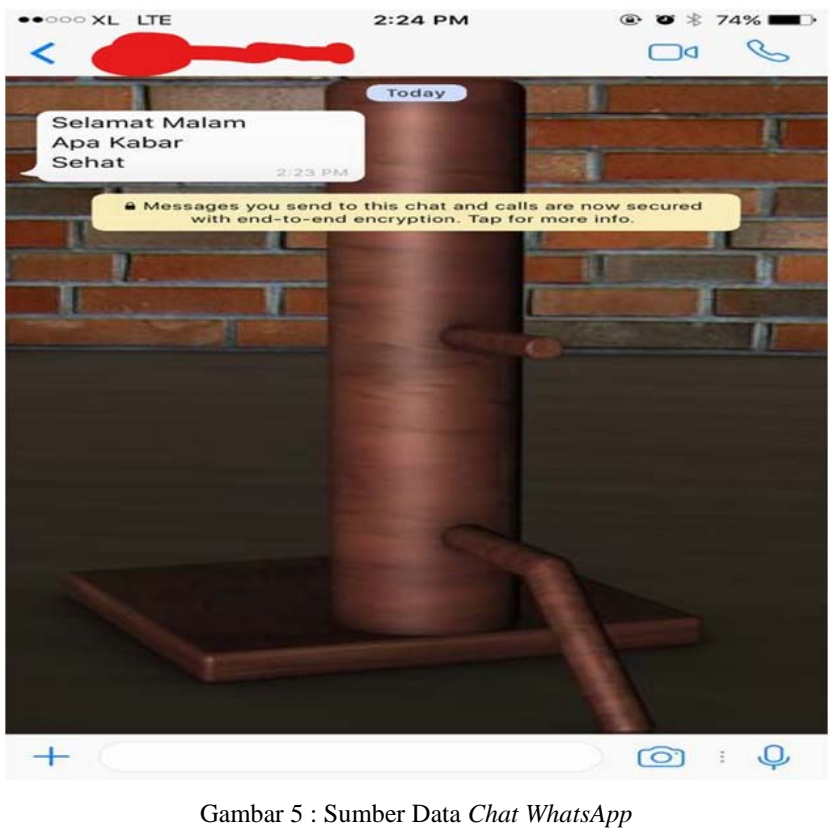

A. Enkripsi

p-ISSN:1693 - 2951; e-ISSN: 2503-2372 
1) Substitusi, Vigenere, dan Transposisi Cipher : dalam proses enkripsi ini akan dimulai dengan enkripsi dengan substitusi, kedua vigenere, dan yang ketiga transposisi.

- Substitusi Cipher dengan Pergeseran 5 ke Kanan

Substitusi cipher dengan pergeseran 5 ke kanan, dapat ditunjukan pada Gambar 6.

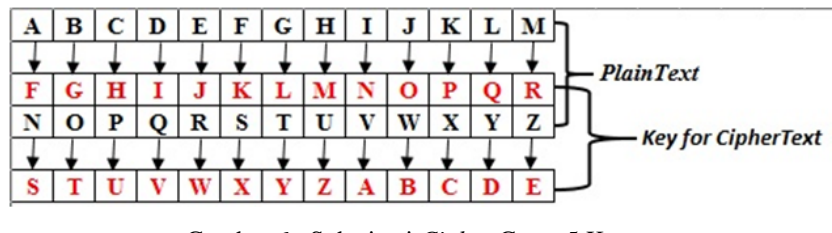

Gambar 6 : Substitusi Cipher Geser 5 Kanan

Merujuk sumber data pada Gambar 5, maka substitusi cipher berdasarkan pada Gambar 6, maka didapakan ciphertext sebagai berikut:

PlainText : SELAMAT MALAM APA KABAR SEHAT CipherText 1 : XJQFRFY RFQFR FUF PFGFW XJMFY

- Vigenere Cipher

Merujuk pada Gambar 3, maka akan didapatkan cipher text kedua sebagai berikut:

CipherText 1 : XJQFRFY RFQFR FUF PFGFW XJMFY

Key $\quad$ : KUNCIKU NCIKU NCI KUNCI KUNCI

CipherText 2 : HDDHZPS EHYPL SWN ZZTHE HDZHG

- Transposisi Cipher Horinsontal lebar 5

Tahap terakhir adalah enkripsi untuk mendapatkan cipher text 3 dari cipher text 2 dengan transposisi secara horinsontal dengan lebar karakter 5.

CipherText 2 : HDDHZPS EHYPL SWN ZZTHE HDZHG

HDDHZ

PSEHY

PLSWN

ZZTHE

HDZHG

Dibaca secara vertikal, maka akan didapatkan cipher text 3 sebagai berikut:

CipherText 3 : HPPZHDS LZDDE STZ HHWHH ZYNEG

Ketiga proses secara ringkas dapat dilihat pada Tabel 1 berikut:

TABEL I

KombinASI 3 METODE

\begin{tabular}{|c|l|l|l|}
\hline \multicolumn{4}{|c|}{ Plain Text } \\
\hline \multicolumn{3}{|c|}{ SELAMAT MALAM APA KABAR SEHAT } \\
\hline Metode & CipherText 1 & CipherText 2 & CipherText 3 \\
\hline Substitusi & XJQFRFY & & \\
& RFQFR FUF & & \\
& PFGFW & & \\
& XJMFY & & \\
\hline Vigenere & & HDDHZPS & \\
& & EHYPL SWN & \\
& & ZZTHE & \\
& & & \\
\hline Transposisi & & & HPPZHDS \\
& & & LZDDE STZ \\
& & & HHWH \\
\hline
\end{tabular}

2) Substitusi dan Vigenere : dalam proses enkripsi ini akan dimulai dengan enkripsi substitusi dan diakhiri dengan enkripsi vigenere.

- Substitusi Cipher dengan Pergeseran 5 ke Kanan

Substitusi cipher dengan pergeseran 5 ke kanan, dapat ditunjukan pada Gambar 6. Dengan data yang sama pada Gambar 5, maka akan didapatkan hasil sebagai berikut:

PlainText : SELAMAT MALAM APA KABAR SEHAT

CipherText 1 : XJQFRFY RFQFR FUF PFGFW XJMFY

- $\quad$ Vigenere Cipher

Merujuk pada Gambar 3, maka akan didapatkan ciphertext kedua berdasarkan cipher text 1 sebagai berikut:

CipherText 1 : XJQFRFY RFQFR FUF PFGFW XJMFY

Key $\quad$ KUNCIKU NCIKU NCI KUNCI KUNCI

CipherText 2 : HDDHZPS EHYPL SWN ZZTHE HDZHG

Kedua proses secara ringkas dapat dilihat pada Tabel 2 berikut:

TABEL II

KOMBINASI SUBSTITUSI DAN VIGENERE CIPHER

\begin{tabular}{|c|l|l|}
\hline Metode & CipherText 1 & CipherText 2 \\
\hline Substitusi & XJQFRFY & \\
& $\begin{array}{l}\text { RFQFR FUF } \\
\text { PFGFW } \\
\\
\text { XJMFY }\end{array}$ & \\
\hline Vigenere & & HDDHZPS \\
& & EHYPL SWN \\
& & ZZTHE \\
& & HDZHG \\
\hline
\end{tabular}

3) Substitusi dan Transposisi : dalam proses enkripsi ini akan dimulai dengan enkripsi substitusi dan diakhiri dengan enkripsi transposisi.

- $\quad$ Substitusi Cipher dengan Pergeseran 5 ke Kanan

Substitusi cipher dengan pergeseran 5 ke kanan, dapat ditunjukkan pada Gambar 6. Dengan data yang sama pada Gambar 5, maka akan didapatkan hasil sebagai berikut:

PlainText : SELAMAT MALAM APA KABAR SEHAT CipherText 1 : XJQFRFY RFQFR FUF PFGFW XJMFY

- Transposisi Horisontal Lebar 5

Selanjutnya adalah enkripsi untuk mendapatkan cipher text 2 dari cipher text 1 dengan transposisi secara horinsontal dengan lebar karakter 5.

CipherText 1 : XJQFRFY RFQFR FUF PFGFW XJMFY

XJQFR

FYRFQ

FRFUF

PFGFW

XJMFY

Dibaca secara vertikal, maka akan didapatkan cipher text 2 sebagai berikut:

CipherText 2 : XFFPXJY RFJQR FGM FFUFF RQFWY 
Majalah Ilmiah Teknologi Elektro, Vol. 17, No. 1,Januari -April 2018

DOI: https://doi.org/10.24843/MITE.2018.v17i01.P08

Kedua proses secara ringkas dapat dilihat pada Tabel 3 berikut:

TABEL III

KOMBINASI SUBSTITUSI DAN TRANSPOSISI CIPHER

\begin{tabular}{|c|l|l|}
\hline Metode & CipherText 1 & \multicolumn{1}{c|}{ CipherText 2 } \\
\hline Substitusi & XJQFRFY & \\
& $\begin{array}{l}\text { RFQFR FUF } \\
\text { PFGFW } \\
\text { XJMFY }\end{array}$ & \\
\hline Transposisi & & $\begin{array}{l}\text { XFFPXJY } \\
\text { RFJQR FGM } \\
\end{array}$ \\
& & FFUFF RQFWY \\
\hline
\end{tabular}

4) Vigenere dan Transposisi : dalam proses enkripsi ini akan dimulai dengan enkripsi vigenere dan diakhiri dengan enkripsi transposisi.

\section{- $\quad$ Vigenere Cipher}

Vigenere cipher, berdasarkan Gambar 3, maka hasil yang akan didapatkan adalah sebagai berikut:

\section{PlainText : SELAMAT MALAM APA KABAR SEHAT}

Key $\quad$ KUNCIKU NCIKU NCI KUNCI KUNCI

CipherText 1 : CYYCUKN ZCTKG NRI UUOCZ CYUCB

- $\quad$ Transposisi Horisontal Lebar 5

Selanjutnya adalah enkripsi untuk mendapatkan cipher text 2 dari cipher text 1 dengan transposisi secara horinsontal dengan lebar karakter 5.

CipherText 1 : CYYCUKN ZCTKG NRI UUOCZ CYUCB

CYYCU

KNZCT

KGNRI

UUOCZ

CYUCB

Dibaca secara vertikal, maka akan didapatkan cipher text 2 sebagai berikut:

CipherText 2 : CKKUCYN GUYYZ NOU CCRCC UTIZB

Kedua proses secara ringkas dapat dilihat pada Tabel 4 berikut:

TABEL IV

KOMBINASI VIGENERE DAN TRANSPOSISI CIPHER

\begin{tabular}{|c|l|l|}
\hline \multicolumn{1}{|c|}{ Metode } & CipherText 1 & CipherText 2 \\
\hline Vigenere & CYYCUKN & \\
& $\begin{array}{l}\text { ZCTKG NRI } \\
\text { UUOCZ }\end{array}$ & \\
& CYUCB & \\
\hline Transposisi & & CKKUCYN \\
& & GUYYZ \\
& & NOU \\
& & CCRCC \\
& & UTIZB \\
\hline
\end{tabular}

M. Azman Maricar: Keamanan Pesan Teks Dengan ...

5) Substitusi Cipher : dalam proses enkripsi ini akan menggunakan substitusi cipher dengan pergeseran 5 ke kanan sesuai dengan Gambar 6 sebagai berikut:

PlainText : SELAMAT MALAM APA KABAR SEHAT

CipherText : XJQFRFY RFQFR FUF PFGFW XJMFY

6) Vigenere Cipher : dalam proses enkripsi ini akan menggunakan vigenere cipher bedasarkan dengan Gambar 3 sebagai berikut:

PlainText : SELAMAT MALAM APA KABAR SEHAT

Key $\quad$ KUNCIKU NCIKU NCI KUNCI KUNCI

CipherText : CYYCUKN ZCTKG NRI UUOCZ CYUCB

7) Transposisi Cipher : dalam proses enkripsi ini akan menggunakan transposisi cipher horisontal dengan lebar 5 sebagai berikut:

PlainText : SELAMAT MALAM APA KABAR SEHAT

SELAM

ATMAL

AMAPA

KABAR

SEHAT

Dibaca secara vertikal, maka akan didapatkan cipher text sebagai berikut:

CipherText : SAAKSET MAELM ABH AAPAA MLART

\section{B. Dekripsi}

1) Transposisi, Vigenere, dan Substitusi Cipher : dalam proses dekripsi ini akan dimulai dengan dekripsi dengan transposisi, kedua vigenere, dan yang ketiga substitusi.

- $\quad$ Transposisi Horisontal Lebar 5

Proses ini untuk mengembalikan ciphet text 3 menjadi cipher text 2, prosesnya sebagai berikut:

CipherText 3 : HPPZHDS LZDDE STZ HHWHH ZYNEG

$\mathrm{HPPZH}$

DSLZD

DESTZ

HHWHH

ZYNEG

Dibaca secara vertikal, maka akan didapatkan cipher text 2 sebagai berikut:

CipherText 2 : HDDHZPS EHYPL SWN ZZTHE HDZHG

- Vigenere Cipher

Proses ini untuk mengembalikan ciphet text 2 menjadi cipher text 1, berdasarkan Gambar 3, maka prosesnya sebagai berikut:

CipherText 2 : HDDHZPS EHYPL SWN ZZTHE HDZHG

Key $\quad$ KUNCIKU NCIKU NCI KUNCI KUNCI

CipherText 1 : XJQFRFY RFQFR FUF PFGFW XJMFY

- $\quad$ Substitusi Pergeseran 5 ke Kiri

Dan proses terakhir adalah mengembalikan plaintext dari ciphertext 1 dengan substitusi pergeseran 5 ke kiri berdasarkan pada Gambar 6, maka prosesnya sebagai berikut: CipherText 1 : XJQFRFY RFQFR FUF PFGFW XJMFY p-ISSN:1693 - 2951; e-ISSN: 2503-2372 
PlainText : SELAMAT MALAM APA KABAR SEHAT

2) Vigenere dan Substitusi Cipher : dalam proses dekripsi ini akan dimulai dengan dekripsi dengan vigenere dan yang kedua substitusi.

\section{- Vigenere Cipher}

Proses ini untuk mengembalikan ciphet text 2 menjadi cipher text 1, berdasarkan Gambar 3, maka prosesnya sebagai berikut:

CipherText 2 : HDDHZPS EHYPL SWN ZZTHE HDZHG

Key $\quad$ KUNCIKU NCIKU NCI KUNCI KUNCI CipherText 1 : XJQFRFY RFQFR FUF PFGFW XJMFY

- $\quad$ Substitusi Pergeseran 5 ke Kiri

Dan proses terakhir adalah mengembalikan plaintext dari ciphertext 1 dengan substitusi pergeseran 5 ke kiri berdasarkan pada Gambar 6, maka prosesnya sebagai berikut: CipherText 1 : XJQFRFY RFQFR FUF PFGFW XJMFY PlainText : SELAMAT MALAM APA KABAR SEHAT

3) Transposisi dan Substitusi : dalam proses dekripsi ini akan dimulai dengan dekripsi dengan transposisi dan yang kedua substitusi.

- $\quad$ Transposisi Horisontal Lebar 5

Proses ini untuk mengembalikan ciphet text 2 menjadi cipher text 1 , prosesnya sebagai berikut:

CipherText 2 : XFFPXJY RFJQR FGM FFUFF RQFWY

XFFPX

JYRFJ

QRFGM

FFUFF

RQFWY

Dibaca secara vertikal, maka akan didapatkan cipher text 1 sebagai berikut:

CipherText 1 : XJQFRFY RFQFR FUF PFGFW XJMFY

- $\quad$ Substitusi Pergeseran 5 ke Kiri

Dan proses terakhir adalah mengembalikan ciphertext 1 menjadi plaintext, dengan substitusi pergeseran 5 ke kiri berdasarkan Gambar 6, maka prosesnya sebagai berikut:

CipherText 1 : XJQFRFY RFQFR FUF PFGFW XJMFY

PlainText : SELAMAT MALAM APA KABAR SEHAT

4) Transposisi dan Vigenere : dalam proses dekripsi ini akan di mulai dengan dekripsi dengan transposisi dan yang kedua vigenere.

- $\quad$ Transposisi Horisontal Lebar 5

Proses ini untuk mengembalikan ciphet text 2 menjadi cipher text 1, prosesnya sebagai berikut:

CipherText 2 : CKKUCYN GUYYZ NOU CCRCC UTIZB

CKKUC

YNGUY

YZNOU

CCRCC

UTIZB

Dibaca secara vertikal, maka akan didapatkan cipher text 1 sebagai berikut:
CipherText 1 : CYYCUKN ZCTKG NRI UUOCZ CYUCB

- Vigenere Cipher

Proses ini untuk mengembalikan ciphet text 1 menjadi plain text, berdasarkan Gambar 3, maka prosesnya sebagai berikut:

CipherText 1 : CYYCUKN ZCTKG NRI UUOCZ CYUCB

Key $\quad$ KUNCIKU NCIKU NCI KUNCI KUNCI

PlainText : SELAMAT MALAM APA KABAR SEHAT

5) Substitusi Cipher : dalam proses dekripsi ini akan menggunakan substitusi cipher dengan pergeseran 5 ke kiri sesuai dengan Gambar 6 sebagai berikut:

CipherText 1 : XJQFRFY RFQFR FUF PFGFW XJMFY PlainText : SELAMAT MALAM APA KABAR SEHAT

6) Vigenere Cipher : dalam proses dekripsi ini akan menggunakan vigenere cipher bedasarkan dengan Gambar 3 sebagai berikut:

CipherText : CYYCUKN ZCTKG NRI UUOCZ CYUCB

Key $\quad$ KUNCIKU NCIKU NCI KUNCI KUNCI

PlainText : SELAMAT MALAM APA KABAR SEHAT

7) Transposisi Cipher : dalam proses enkripsi ini akan menggunakan transposisi cipher horisontal dengan lebar 5 sebagai berikut:

CipherText : SAAKSET MAELM ABH AAPAA MLART

SAAKS

ETMAE

LMABH

AAPAA

MLART

Dibaca secara vertikal, maka akan didapatkan plain text sebagai berikut:

PlainText : SELAMAT MALAM APA KABAR SEHAT

\section{Perbandingan Efektivitas Metode}

Ketiga metode yang digunakan yaitu, substitusi, vigenere, dan transposisi cipher akan dibandingkan berdasarkan keefektifan yang tolak ukurnya adalah ukuran file dan waktu yang dibutuhkan untuk melakukan proses kriptografi pada masing-masing kombinasi metode. Sebagai alat penelitian guna melakukan pengukuran terhadap ukuran file dan waktu proses, akan digunakan software Cryptool. Dengan menggunakan software tersebut didapatkan hasil yang dapat dilihat pada Tabel 5 berikut:

TABLE V

HASIL PENGUKURAN METODE

\begin{tabular}{|l|l|l|l|}
\hline Kombinasi Metode & Ukuran File & Waktu & Proses \\
\hline $\begin{array}{l}\text { Substitusi, } \\
\text { Vigenere, dan } \\
\text { Transposisi }\end{array}$ & $11 \mathrm{~Kb}$ & $00: 01: 54$ & Berhasil \\
\hline $\begin{array}{l}\text { Substitusi dan } \\
\text { Vigenere }\end{array}$ & $7 \mathrm{~Kb}$ & $00: 01: 34$ & Berhasil \\
\hline $\begin{array}{l}\text { Substitusi dan } \\
\text { Transposisi }\end{array}$ & $9 \mathrm{~Kb}$ & $00: 01: 41$ & Berhasil \\
\hline $\begin{array}{l}\text { Vigenere dan } \\
\text { Transposisi }\end{array}$ & $9 \mathrm{~Kb}$ & $00: 00: 43$ & Berhasil \\
\hline
\end{tabular}




\begin{tabular}{|l|l|l|l|}
\hline Substitusi & $5 \mathrm{~Kb}$ & $00: 00: 37$ & Berhasil \\
\hline Vigenere & $5 \mathrm{~Kb}$ & $00: 00: 41$ & Berhasil \\
\hline Transposisi & $6 \mathrm{~Kb}$ & $00: 01: 43$ & Berhasil \\
\hline
\end{tabular}

Chatting. Jurnal Sistem dan Informatika, Mei 2016; Vol.10 No.2 : p.119-127.

[10] I Wayan Manik Suhartanta dan Nyoman Putra Sastra. Survey Tingkat Penggunaan Single Sign On pada 500 Situs Peringkat Teratas Alexa.com. Teknologi Elektro, Januari-April 2017; Vol.16 No.1 : p.4952.

\section{KESIMPULAN}

Dari penelitian yang dilakukan didapatkan hasil bahwa dari tujuh kombinasi metode yang diproses, dinyatakan berhasil dilakukan proses enkripsi dan dekripsi. Dalam perbandingan efektivitas, digunakan dua alat ukur, yaitu ukuran file dan waktu proses.

Berdasarkan ukuran file, didapatkan hasil untuk ukuran file terbesar adalah kombinasi metode Substitusi, Vigenere, dan Transposisi dengan ukuran file $11 \mathrm{~Kb}$. Sedangkan untuk ukuran file terkecil adalah metode Substitusi dan metode Vigenere dengan ukuran file $5 \mathrm{~Kb}$.

Berdasarkan waktu prosesnya, didapatkan hasil untuk waktu terlama adalah kombinasi metode Substitusi, Vigenere, dan Transposisi dengan waktu 1.54 detik. Sedangkan waktu tercepat adalah metode Substitusi dengan waktu 0.37 detik.

Ukuran file yang lebih besar dan waktu proses yang terlama, menandakan bahwa kombinasi tiga metode yaitu Substitusi, Vigenere, dan Transposisi Cipher merupakan kombinasi dengan kompleksitas algoritma yang tinggi dibandingkan dengan kombinasi lainnya yaitu Substitusi Vigenere, Substitusi Transposisi, Vigenere Transposisi, Substitusi, Vigenere, dan Transposisi.

\section{REFERENSI}

[1] M.Miftakul Amin. Implementasi Kriptografi Klasik Pada Komunikasi Berbasis Teks. Jurnal Pseudocode, September 2016; Vol.3 No.2 : p.129-136.

[2] I Putu Agus Eka Darma Udayana dan Nyoman Putra Sastra. Perbandingan Performansi Pengamanan File Backup LPSE Menggunakan Algoritma DES dan AES. Teknologi Elektro, JanuariJuni 2016; Vol.15. No.1 : p.111-117.

[3] Hamdani. Perbandingan Metode Vigenere dan Affine Untuk Pesan Rahasia. Jurnal Informatika Mulawarman, Juli 2012; Vol.7 No.2 : p.70-74.

[4] Fresly Nandar Pabokory, Indah Fitri Astuti, dan Awang Harsa Kridalaksana. Implementasi Kriptografi Pengamanan Data Pada Pesan Teks, Isi File Dokumen, Dan File Dokumen Menggunakan Algoritma Advanced Encryption Standard. Jurnal Informatika Mulawarman, Februari 2015; Vol.10 No.1 : p.20-31.

[5] Irham Mu'alimin Arrijal, Rusdi Efendi, dan Boko Susilo. Penerapan Algoritma Kriptografi Kunci Simetris Dengan Modifikasi Vigenere Cipher Dalam Aplikasi Kriptografi Teks. Jurnal Pseudocode, Februari 2016; Vol.3 No.1 : p.69-82.

[6] Sri Andayani dan Dionysius Spironabel Agista. Kriptografi Klasik Teknik Subsitusi Untuk Keamanan Data Menggunakan Vb.Net 2008. Jurnal Matrix, Juli 2014; Vol.4 No.2 : p.75-80.

[7] Atmaja Basuki, Upik Paranita, dan Restu Hidayat. Perancangan Aplikasi Kriptografi Berlapis Menggunakan Algoritma Caesar, Transposisi, Vigenere, Dan Blok Chiper Berbasis Mobile. Seminar Nasional Teknologi Informasi dan Multimedia, 2016; p.1.2-31 - 1.235.

[8] Akim Manaor Hara Pardede dan Yani Maulita. Perancangan Perangkat Lunak Enkripsi Dan Deskripsi File Dengan Metode Transposisi Kolom. Jurnal Kaputama, Juli 2014; Vol.8 No.1 : p.28-35.

[9] Gede Angga Pradipta. Penerapan Kombinasi Metode Enkripsi Vigenere Chiper Dan Transposisi Pada Aplikasai Client Server

M. Azman Maricar: Keamanan Pesan Teks Dengan ... 